This is the author's final, peer-reviewed manuscript as accepted for publication. The publisher-formatted version may be available through the publisher's web site or your institution's library.

\title{
Production of Autopolyploid Lowland Switchgrass Lines Through In Vitro Chromosome Doubling
}

Zhiyong Yang \& Zhengxing Shen \& Hannah Tetreault \& Loretta Johnson \& Bernd Friebe \& Taylor Frazier \& Lin-kai Huang \& Caitlin Burklew \& Xin-Quan Zhang \& Bingyu Zhao

\section{How to cite this manuscript}

If you make reference to this version of the manuscript, use the following information:

Yang, Z., Shen, Z, Tetreault, H., Johnson, L., Friebe, B., Frazier, T., Huang, L. K., Burklew, C., Zhang, X. Q., \& Zhao, B. (2014). Production of Autopolyploid Lowland Switchgrass Lines Through In Vitro Chromosome Doubling. Retrieved from http://krex.ksu.edu

\section{Published Version Information}

Citation: Yang, Z., Shen, Z, Tetreault, H., Johnson, L., Friebe, B., Frazier, T., Huang, L. K., Burklew, C., Zhang, X. Q., \& Zhao, B. (2014). Production of Autopolyploid Lowland Switchgrass Lines Through In Vitro Chromosome Doubling. Bioenergy Research, 7(1), 232-242.

Copyright: @ Springer Science+Business Media New York 2013

Digital Object Identifier (DOI):10.1007/s12155-013-9364-x

Publisher's Link: http://link.springer.com/article/10.1007/s12155-013-9364-x

This item was retrieved from the K-State Research Exchange (K-REx), the institutional repository of Kansas State University. K-REx is available at http://krex.ksu.edu 
Title: Production of autooctoploid lowland switchgrass lines through in vitro chromosome doubling

Zhiyong Yang ${ }^{1,2}$, Zhengxing Shen ${ }^{1}$, Hannah Tetreault ${ }^{3}$, Loretta Johnson ${ }^{3}$, Bernd Friebe ${ }^{4}$, Taylor Frazier $^{1}$, Lin-kai Huang ${ }^{1,5}$, Bin Xu ${ }^{1}$, Xin-Quan Zhang ${ }^{5}$, Bingyu Zhao ${ }^{* 1}$,

1. Department of Horticulture, Virginia Polytechnic Institute and State University, Blacksburg, VA, 24060; 2. The Institute of Critical Technology and Applied Sciences (ICTAS) of Virginia Tech; 3. Division of Biology, Kansas State University, Manhattan, KS, 66506; 4. Department of Plant Pathology, Kansas State University, Manhattan, KS, 66506; 5. College of Animal Science and Technology, Si Chuan Agricultural Sciences, Ya-an, Si Chuan, China.

* Corresponding author: Bingyu Zhao

Phone: (540)231-1146

Fax: (540)231-3083

Email: bzhao07@ vt.edu

Latham Hall 420, Virginia Tech, Blacksburg, VA, 24061

\section{Abstract}

Switchgrass is considered one of the most promising energy crops. However, breeding of elite switchgrass cultivars is required to meet the challenges of large scale and sustainable biomass production. As a native perennial adapted to North America, switchgrass has lowland and upland ecotypes, where most lowland ecotypes are tetraploid $(2 n=4 x=36)$, and most upland ecotypes are predominantly octoploid $(2 n=8 x=72)$. Hybridization between lowland and upland switchgrass plants could identify new cultivars with heterosis. However, crossing between tetraploid and octoploid switchgrass is rare in nature. Therefore, in order to break down the cross incompatibility barrier between tetraploid lowland and octoploid upland switchgrass lines, we developed autooctoploid switchgrass lines from the lowland tetraploid cv. Alamo. In this study, colchicine was used in liquid and solid mediums to chemically-induce chromosome doubling in embryogenic calli derived from cv. Alamo. Thirteen autooctoploid switchgrass lines were regenerated from seedlings and identified using flow cytometry. The autooctoploid switchgrass plants exhibit increased stomata aperture and stem size in comparison with the tetraploid cv. Alamo. The most autooctoploid plants were regenerated from switchgrass calli that were treated 
with $0.04 \%$ colchicine in liquid medium for 13 days. One autooctoploid switchgrass line, VT8-1, was successfully crossed to the octoploid upland cv. Blackwell. The autooctoploid and the derived inter-ecotype hybrids were confirmed by chromosome in-situ hybridization and molecular marker analysis. Therefore, the results of this study show that an autooctoploid, generated by chemically-induced chromosome doubling of lowland cv. Alamo, is cross compatible with upland octoploid switchgrass cultivars. The outcome of this study may have significant applications in switchgrass hybrid breeding.

\section{Keywords}

Bioenergy. Switchgrass. Autooctoploids. Chromosome doubling. Cytogenetics. Biofeedstocks

\section{Introduction}

Switchgrass (Panicum virgatum, L.), a perennial C4 plant native to the North American grasslands, has garnered considerable attention for its potential use as a cellulosic biofuel crop due to its broad adaptability to diverse growing conditions, its high biomass yield, its ability to sequester the greenhouse gas $\mathrm{CO}_{2}$, and its ability to prevent the degradation of agricultural soils [1]. However, breeding of elite switchgrass cultivars is required to meet the challenges of large scale and sustainable biomass production. Switchgrass breeding programs that target biomass improvement have recently been initiated in the United States.

Switchgrass has two major ecotypes that originate from different habitats. The lowland ecotypes are generally adapted to southern, warm, moist habitats, whereas the upland ecotypes are better adapted to the northern U.S. and southern Canada. In general, lowland ecotypes produce more biomass and are resistant to major switchgrass diseases; however, they are more sensitive to abiotic stresses such as cold and drought [2, 3]. Upland ecotypes produce less biomass but are more tolerant to abiotic stresses [1, 4-6]. It is ideal to generate inter-ecotype switchgrass hybrids with combined desirable traits from both lowland and upland ecotypes. Cytogenetic studies have revealed that most lowland ecotypes are tetraploid $(2 n=4 x=36)$, whereas the upland ecotypes are primarily octoploid $(2 n=8 x=72)[1,5]$.

Switchgrass is open-pollinated and highly self-incompatible, which favors natural hybridization $[1,5,6]$. In nature, switchgrass plants with the same ploidy level can usually be easily intercrossed regardless of ecotype; however, hybrids between different ploidy levels are very rare [7,8]. Due to the ploidy barrier, genetic flow between upland and lowland ecotypes is limited, which has ultimately maintained a high level of genetic diversity in switchgrass 
germplasm [9-14]. Hybrid breeding, which has significantly impacted modern agriculture, is a method of creating new cultivars by crossing between genetic lines that have different backgrounds [15]. For instance, corn yield has tripled in the last 60 years through hybrid breeding [16]. The naturally isolated genetic reservoirs of the two switchgrass ecotypes may allow breeders to create superior biomass hybrids by crossing between them. Correspondingly, a recent report has demonstrated that hybrids derived from a cross between the tetraploid upland cv. Summer and the lowland cv. Alamo, produce more biomass than either parental line [17]. However, because of their cross incompatibility, there have been no reports of switchgrass cultivars derived from crossing between tetraploid lowland and octoploid upland germplasm. Artificial crosses between tetraploid and octoploid switchgrass cultivars have been attempted using the embryo-rescue method [7, 18]. However, the derived hexaploid plants are weak, unstable, and infertile [7, 18]. Therefore, methods that would allow breeders to easily generate interploidy hybrids, by crossing upland and lowland switchgrass cultivars, could provide novel inter-ecotype hybrids with improved agronomic traits. Autooctoploid lowland ecotypes could be generated through chromosome doubling, and would then be cross-compatible with the natural octoploid upland switchgrass ecotypes. Presently, there have been no reports about generating autooctoploid switchgrass lines through chromosome doubling, though such kind of breeding efforts have been frequently used in many other plant species [19-25].

Chromosome doubling can be induced by treating the plant tissue with heat or cold shock $[26,27]$, or by treating with antimitotic agents like NO gas [28], colchicine [24, 29], oryzalin [24, 30], and trifluralin [31]. Because antimitotic chemical treatment is relatively easy to perform and the results are reproducible, it is the most frequently used method for inducing chromosome doubling in many plant species $[24,32]$. However, the antimitotic chemical concentration and the treatment duration needs to be systematically evaluated in order to develop efficient and effective chromosome doubling methods in a given plant species [24, 32]. In this report, we developed an efficient chromosome doubling system to regenerate octoploid switchgrass lines from somatic embryogenic (SE) calli treated with the antimitotic chemical colchicine. Thirteen autooctoploid lowland switchgrass lines were regenerated from the tetraploid cv. Alamo. Hybrids were successfully obtained by crossing one autooctoploid line, VT8-1, with the upland octoploid cv. Blackwell. The autooctoploid lowland switchgrass lines derived from chromosome 
doubling are valuable resources that will allow breeders to transfer genetic elements from lowland to upland ecotypes by regular crossing and selection.

\section{Materials and Methods}

\section{Plant materials}

Switchgrass seeds of cv. Alamo and cv. Blackwell were originally obtained from the USDA-NRCS Plant Material Center (Knox City, TX), and maintained in both the greenhouse as well as the Kentland Experimental Farm of Virginia Tech. Mature seeds were harvested and stored at $4{ }^{\circ} \mathrm{C}$ before use. The switchgrass genotype HR8 [33], derived from cv. Alamo, which has an exceptional tissue culture capacity as well as a high germination rate, was used to induce somatic embryogenic (SE) calli in this study. The SE calli were induced from mature switchgrass seeds of HR8 as described below. All regenerated plants were transplanted into soil and maintained in the greenhouse, which is programmed with temperatures set at $28{ }^{\circ} \mathrm{C} /$ day and $22{ }^{\circ} \mathrm{C} /$ night with 12-14 hour light.

\section{Plant tissue culture}

Switchgrass tissue culture was performed as described previously [33]. In brief, mature switchgrass seeds were dehulled in $60 \%$ sulfuric acid for $30 \mathrm{~min}$, and then sterilized with $50 \%$ bleach for $45 \mathrm{~min}$ at room temperature. Following this step, the seeds were rinsed four times with sterile water. The sterilized seeds were placed on Petri dishes containing about $20 \mathrm{ml}$ of callus induction (CI) medium (Table 1). About 30 seeds were placed per 100-mm plate. The plates were incubated in the dark at $29{ }^{\circ} \mathrm{C}$ in a growth chamber. SE calli were induced about four weeks after transferring the seeds onto CI medium.

SE calli derived from a single switchgrass seed were selected and subcultured on fresh medium every two weeks. This process allowed us to generate uniform SE callus lines derived from single seeds that may have a homogenous genetic background, though somatic mutations could have occurred during the tissue culture steps. Each SE callus line was subcultured for about 2 months to accumulate enough calli for colchicine treatment. 


\section{Colchicine treatment}

Colchicine was purchased from Sigma (St. Louis, MO). A stock solution was made by dissolving the colchicine in ethanol to a final concentration of $4 \mathrm{mg} / \mathrm{ml}$, and stored in the dark at room temperature. The SE calli from each callus line were treated with different concentrations of colchicine in solid or liquid CI medium (Table 1). Some calli from each SE callus line, without colchicine treatment, were used to regenerate seedlings that served as tetraploid controls. For treatment in solid medium, small pieces of callus $(2-3 \mathrm{~mm}$ in diameter) were cultured on CI medium supplemented with colchicine at $0.01 \%, 0.02 \%$, and $0.03 \%$ for 2, 6, or 13 days. For treatment in liquid culture, the SE calli were cultured in $50 \mathrm{ml}$ of liquid CI medium supplemented with colchicine at $0.02 \%, 0.04 \%$, and $0.06 \%$ for $2,4,6$, or 13 days in a $250 \mathrm{ml}$ flask with constant shaking at $120 \mathrm{rpm}$ at $29{ }^{\circ} \mathrm{C}$. After treatment, the calli were washed two times with liquid CI medium to remove the residual colchicine. The washed calli were transferred to regeneration medium (RG) (Table 1) and incubated under continuous light (140 $\mu \mathrm{mol} / \mathrm{m}^{2} / \mathrm{s} \mathrm{cool} \mathrm{white} \mathrm{fluorescent} \mathrm{irradiance)} \mathrm{at} 29{ }^{\circ} \mathrm{C}$ in a growth chamber. Once the regenerated seedlings developed intact root systems, the plantlets were transplanted into soil and maintained in the greenhouse. All tissue culture chemicals were purchased from PhytoTechnology Laboratory Inc. (Shawnee Mission, KS).

Measurement of the switchgrass stomata and epidermal cell sizes

The second mature leaf from the top of each untreated control or colchicine treated switchgrass line was used to obtain the stomata and epidermal cell layer imprints. A thin layer of nail varnish was painted onto the adaxial and abaxial surfaces of each selected leaf at similar positions. After 30 minutes, the thin layer of varnish, which was coated on the surface, was carefully peeled off. The varnishes with imprints of stomata and epidermal cells were positioned onto slides for examination and photographed with a light microscope.

Flow cytometry analysis of nuclei DNA content of switchgrass plants 
The nuclear DNA content of switchgrass plants was determined by using a Cystain PI absolute P kit (Partec GmbH, Germany) following the manufacturer's instruction. In brief, about $1 \mathrm{~cm}^{2}$ of switchgrass leaf tissue was chopped with a sharp razor blade in nuclei extraction buffer. The extracted nuclei were stained with propidium iodide supplemented with RNase. The fluorescent signal of stained nuclei was measured using the flow cytometer (Model FACSAria II, BD Biosciences, San Jose, CA) at the core facility of the Virginia-Maryland Veterinary School of Virginia Tech. Plant cell ploidy composition was measured by comparing the peaks in the nuclear DNA histogram for the treated regenerated plant with that of the untreated tetraploid control plant. Every plant line was measured three times and the representative data has been presented.

\section{Chromosome analysis and fluorescent in situ hybridization (FISH)}

The collection of meristematic tissues, enzymatic treatment, and slide preparation followed that of Kato (1999) [31]. Plants were grown in the greenhouse with well-watered vermiculite to promote meristem root growth. Healthy, young roots were placed in $2.0 \mathrm{~mL}$ eppendorf tubes, with a mist of water to keep the tips from desiccating. Then, a hole was punctured in the cap to allow for gas flow. Tubes were immediately placed into a gas chamber and treated with nitrous-oxide for 3 hours. After treatment, the tips were fixed on ice with $90 \%$ glacial acetic acid for 10 minutes, and washed three times with $70 \%$ ethanol. Root tips were then stored at $-20^{\circ} \mathrm{C}$ in $70 \%$ ethanol for future use in slide preparation and fluorescent in situ hybridization.

In $1.5 \mathrm{~mL}$ eppendorf tubes, the root tips were washed for ten minutes with constant changes of distilled water. After washing, the root tips were subjected to a potassium chloride buffer ( $\mathrm{pH} 4.0$ ) for 5 minutes in order to lower the $\mathrm{pH}$ for the next step. Each root tip was taken out of solution and dried by rolling on filter paper. The root cap was excised and discarded. The actively dividing region of the tip (about $1.0-1.5 \mathrm{~mm}$ ) was dissected and placed into a $0.5 \mathrm{ml} \mathrm{PCR}$ tube aliquoted with $20 \mu \mathrm{l}$ of enzyme solution (1\% pectolyase Y-23 and $2 \%$ cellulase Onozuka R10 dissolved in citric buffer). The enzymatic reaction was carried out at $37^{\circ} \mathrm{C}$ for 45 minutes. The enzyme treatment was terminated with the addition of TE buffer and the root tips were placed on ice for 5 minutes. Next, the root tips were dehydrated with 3 changes of $100 \%$ ethanol. After 
removing the final ethanol wash, 21-28 $\mu 1$ of freshly made 9:1 glacial acetic acid to methanol was added to each tube, depending on the size of the root tips. Cells were suspended by gently crushing the root tips with a rounded dissection needle. The suspended cells were then dropped onto slides in $7 \mu 1$ droplets, making three to four slides per root tip. Slides were scanned for spreads and placed into the UV cross-linker (Stratalinker UV, Stratagene, La Jolla, CA).

FISH was performed with clone pTa71 derived from common wheat, Triticum aestivum L. Clone pTa71 is a $9 \mathrm{~kb}$ EcoRI fragment of the $18 \mathrm{~S}-25 \mathrm{~S}$ rDNA containing the coding sequences of the $18 \mathrm{~S}, 5.8 \mathrm{~S}$, and $25 \mathrm{~S}$ rDNA genes as well as the intergenic spacer sequence [34]. The probe was labeled with fluorescein-12-dUTP using nick translation [28, 32]. Chromosome spreads were covered with $5 \mu \mathrm{l}$ of salmon sperm DNA (140ng/ $\mu \mathrm{l})$ and plastic coverslips. Then the slides were placed in a moist metal tray in a $100^{\circ} \mathrm{C}$ water bath for 5 minutes in order to denature the DNA and block for background noise. FISH probes for each spread were prepared by diluting $1 \mu \mathrm{l}$ of probe in $4 \mu \mathrm{l} 2 \mathrm{xSSC}$ and denaturing the probe at $100^{\circ} \mathrm{C}$ for 5 minutes. The probes were then placed immediately on ice. Chromosome spreads were cooled on a metal plate on ice before adding the probe to each slide. Slides were incubated in an airtight humidified chamber supplemented with $2 \mathrm{xSC}$ and placed overnight at $55^{\circ} \mathrm{C}$ in an incubation chamber. The following morning, slides were washed in 2x SSC for 5 minutes at room temperature and then washed for 20 minutes with $2 x \mathrm{SSC}$ at $55^{\circ} \mathrm{C}$. After the 20 minute wash, each slide was air dried and Vectashield with propidium iodide for nuclear counterstain was dropped onto each spread. Glass coverslips were gently placed on top of the spreads and images were captured using a SPOT2.1 charge-coupled device (CCD) camera (Diagnostic Instruments, Sterling Heights, MI, USA) and an epifluorescence Zeiss Axioplan 2 phase contrast and fluorescence microscope. Images were processed using Adobe Photoshop CS3 (Version 10.0.1, Adobe Systems Incorporated, San Jose, CA, USA).

Analysis of regenerated switchgrass plants with molecular markers

Plant genomic DNA was extracted using the CTAB method as described previously [35]. Sequence-related amplified polymorphism (SRAP) [36, 37] was performed to distinguish 
between lowland and upland switchgrass ecotypes using Primers me9: 5'TGAGTCCAAACCGGTAG-3' and em13: 5'-GACTGCGTACGAATTAGC-3'. Three pairs of SRAP primers M1 (me1: 5'-TGAGTCCAAACCGGATA-3 and em1: 5'GACTGCGTACGAATTAAT-3'), M2 (me2: 5'-TGAGTCCAAACCGGAGC-3' and em2: 5'GACTGCGTACGAATTTGC-3'), and M3 (me3:5'-TGAGTCCAAACCGGAAT-3 and em3: 5'GACTGCGTACGAATTGAC-3') were used to genotype the hybrid plants derived from the 'Blackwell x VT8-1' cross. The SRAP-PCR amplification program involved one cycle at $94^{\circ} \mathrm{C}$ (5 min), followed by five cycles at $94^{\circ} \mathrm{C}(1 \mathrm{~min}), 35^{\circ} \mathrm{C}(1 \mathrm{~min})$, and $72^{\circ} \mathrm{C}(1 \mathrm{~min})$. An additional 35 cycles at $94^{\circ} \mathrm{C}(1 \mathrm{~min}), 50^{\circ} \mathrm{C}(1 \mathrm{~min})$, and $72^{\circ} \mathrm{C}(1 \mathrm{~min})$ was performed and the program concluded with one final extension at $72^{\circ} \mathrm{C}(10 \mathrm{~min})$. The PCR fragments were separated in a $2 \%$ agarose gel, stained with ethidium bromide, and visualized under UV light using the GelDocument system (Bio-Rad, Hercules, CA).

\section{Measure the agronomic traits of switchgrass plants}

To characterize the agronomic traits of the synthetic autooctoploid plants, twenty VT8-1, VT8-2, and HR8 plants were propagated by splitting tillers and replanting them in the Kentland Farm of Virginia Tech in 2010. Seventy-eight hybrid seedlings derived from the VT8-1 x Blackwell cross and the Blackwell x VT8-1 cross were germinated in the greenhouse and 2month old seedlings were then transplanted into the field. The hybrid plants were planted as three blocks, each block including six plants of VT8-1, six plants of VT8-2, and six plants of HR8. All plants were planted as 4 inches $\mathrm{x} 4$ inches. At the end of the growing season, at least five plants for each line were randomly chosen to measure selected agronomic traits. The above ground biomass of each plant was collected and dried in an oven at $60^{\circ} \mathrm{C}$ for 3 days. The weight of the dry biomass was then measured. To measure the stem size, we randomly selected 10 flowering tillers of each line and measured the $2^{\text {nd }}$ node above the ground. To measure the leaf size, we randomly chose 10 flag leaves of the flowering tillers to measure the leaf length and width. Ten randomly selected flowering tillers were then chosen for measuring the plant height.

\section{Statistical Analysis}


Data for all samples, with at least 5 replicates, were analyzed using $t$-tests with software JMP version 7 (SAS Institute, Inc., Cary NC) in order to detect significant differences between the autooctoploid and control plants.

\section{Results}

Production of autooctoploid lowland switchgrass lines from tetraploid cv. Alamo

Initial attempts to generate autooctoploid switchgrass lines from the tetraploid lowland cv. Alamo were inefficient. SE calli were treated in liquid MS medium supplemented with $0.1 \%$ colchicine for 24 and 48 hours (data not shown). The treated calli were then regenerated into seedlings and the plantlets were screened, using flow cytometry, for doubled nuclear-DNA content. In this screen, we identified only two putative autooctoploid lines, VT8-1 and VT8-2. To develop a more efficient protocol for colchicine-induced chromosome doubling of switchgrass, we repeated the experiment with more treatments, which led us to generate eleven additional autooctoploid lines.

\section{Effect of colchicine treatments on SE calli}

Switchgrass SE calli, derived from single seeds, were treated in either solid or liquid CI medium supplemented with different concentrations of colchicine for various lengths of time. With solid medium treatment, the SE calli were treated under nine treatment conditions (Table 2). A small portion of SE callus, from each callus line, was also regenerated into plantlets without colchicine treatment. These plants were used as the tetraploid controls in flow cytometry analysis. For all solid medium treatments, a total of 582 treated calli were placed on RG medium and of these, 561 regenerated green seedlings. Therefore, on average, more than $90 \%$ of treated SE calli were able to regenerate into green seedlings from the solid medium treatment. In general, higher concentrations and longer treatments with colchicine reduced the regeneration ability of the treated switchgrass calli (Table 2). However, when treated on solid medium supplemented with $0.06 \%$ colchicine for 13 days, more than $68 \%$ of treated SE calli were still able to regenerate into seedlings. Therefore, even higher concentrations and longer durations could be applied to 
switchgrass calli under solid medium treatment. To test the efficiency of chromosome doubling under these different conditions, six plantlets from each treatment were randomly sampled for flow cytometry analysis. Fifty-four plantlets, derived from nine treatments with solid medium, were screened by flow cytometry, leading us to identify four plants with doubled nuclear DNA content (Table 2).

With liquid medium treatment, a total of 1,226 SE calli were treated under twelve treatment conditions (Table 3). When placed on RG medium, a total of 548 calli regenerated into seedlings. The average regeneration rate for treatment using liquid medium was $44.69 \%$. Ten plants were randomly sampled from each treatment and were analyzed by flow cytometry. After screening 115 plants, we identified seven plants with doubled nuclear DNA content (Table 3).

In general, switchgrass calli were more sensitive to liquid medium treatment (Table 2), which regenerated fewer seedlings in comparison with the solid medium treatment. For example, when SE calli were treated with both solid and liquid mediums supplemented with $0.02 \%$ colchicine for 2, 6, and 13 days, the average callus regeneration rate from liquid treatment was $40 \%$, whereas the average regeneration rate obtained from solid medium treatment was $68 \%$. When the calli were treated in liquid medium supplemented with $0.06 \%$ colchicine for 13 days, most calli died (Figure 1). For this particular treatment, only nine seedlings were regenerated from a total of 108 treated calli (Table 2). Interestingly, when SE calli were treated on solid medium supplemented with $0.01 \%$ colchicine for 2, 6 and 13 days, no octoploid plants were identified. These results indicate that these treatment conditions are not effective for inducing chromosome doubling in vitro (Table 2). Additionally, we found that we could obtain a relative balance of the effects using 13-day treatments with $0.03 \%$ colchicine in solid medium and $0.04 \%$ colchicine in liquid medium (Table 2).

In summary, when testing colchicine concentrations ranging from $0.01 \%$ to $0.06 \%$, our results indicate that optimizing the length of treatment duration, instead of altering the colchicine concentration, was more effective for achieving a higher efficiency of switchgrass chromosome doubling. We also found that colchicine concentrations higher than $0.06 \%$ have significant toxic effects on switchgrass callus.

Generating hybrid seeds between the synthetic autooctoploid and natural octoploid switchgrass lines by traditional crossing 
Our initial efforts for chromosome doubling only resulted in two putative autooctoploid lines, VT8-1 and VT8-2 (Figure 6). In this study, we tried to test if VT8-1 was cross compatible with a natural octoploid, the upland cv. Blackwell. VT8-1 was successfully crossed to cv. Blackwell by bagging tillers of the two plants, before flowering, in the summer of 2009 . We also bagged single tillers of VT8-1, VT8-2, and HR8 plants in an attempt to generate self-crossed seeds; however, no seeds were obtained from any self-crossed tillers. Our results reconfirmed that switchgrass is highly self-incompatible [38]. We have also demonstrated that the selfincompatibility trait was not lost in the synthetic autooctoploid plants. Attempts were also made to obtain hybrid seeds between plants of different ploidy levels by natural crossing. However, no viable hybrid seeds were obtained from the attempted crosses of VT8-1 $(2 n=8 x)$ x HR8 $(2 n=4 x)$ or Blackwell $(2 n=8 x) \times$ HR8 $(2 n=4 x)$. This further confirms that natural crosses/hybrids between different ploidy levels are rare. However, more than 100 viable hybrid seeds were obtained from the cross of 'Blackwell x VT8-1'. Most of the hybrid seeds germinated into robust seedlings that have been transplanted into the Kentland Experimental Farm of Virginia Tech for further study.

\section{Chromosomal constitutions of regenerated autooctoploid plants}

To further study the autooctoploids and the derived hybrids, the chromosomal constitutions of VT8-1, VT8-2, their parent line HR8, and the hybrid lines derived from VT8-1 x Blackwell, were determined using FISH. Our results show that line HR8 is an aneuploid with $2 n=38$ chromosomes. FISH, using pTa71 as a probe, detected two pairs of telomeric hybridization sites (Figure 4). A similar pTa71 FISH pattern was previously observed in all tetraploid accessions of switchgrass analyzed [39]. This indicates that the number and location of nucleolus organizer regions (NORs) in tetraploid accessions is highly conserved.

The autooctoploid line VT8-1 is also an aneuploid with $2 n=78$ chromosomes. FISH, using pTa71 as a probe, detected four pairs of telomeric hybridization sites (Figure 4). The related sister line, VT8-2, had $2 n=76$ chromosomes and also contained four pairs of telomeric pTa71 hybridization sites (Figure 4). The pTa71 FISH patterns of lines VT8-1 and VT8-2 were expected because these lines are autooctoploids derived from the tetraploid parental line HR8. However, this pattern is unique and very different from the octoploid accessions of switchgrass that were previously analyzed [39]. Those octoploid accessions were highly variable in NOR size 
and number and also differed in the chromosomal location of the probe. This clearly confirms that the synthetic autooctoploid lines, VT8-1 and VT8-2, were derived from the tetraploid line HR8.

Line A8-B8 was derived from the cross of VT8-1 x Blackwell. Assuming that the line Blackwell (B) is euploid with $2 n=72$ chromosomes, the hybrid between both lines was expected to have $2 n=74$ chromosomes. However, this line had $2 n=72$ chromosomes, with three chromosomes having telomeric pTa71 FISH sites in both arms, four telomeric pTa71 FISH sites, and one interstitial pTa71 FISH site (Figure 4). The four telomeric pTa71 FISH sites are most likely derived from the parental line VT8-1, whereas the remaining pTa71 FISH sites were contributed from the Blackwell parent.

\section{Confirmation of the identity of synthetic octoploid and hybrid plants}

In order to confirm the genotype of the synthetic autooctoploid and its derived hybrids, we performed PCR-based, molecular marker analysis on VT8-1, Blackwell, and one derived hybrid plant using three pairs of SRAP primers (M1, M2, and M3)[40]. As shown in Figure 5, the hybrid plant, derived from Blackwell x VT8-1, showed combined PCR amplification patterns of both VT8-1 and Blackwell. This result confirms that the hybrid seeds contain genetic information from both switchgrass parental lines. A similar PCR analysis was performed to validate the genotype of all hybrids derived from the autooctoploid plants (data not shown). Therefore, we conclude that VT8-1 plants are synthetic autooctoploid switchgrass plants, which can be easily crossed to natural octoploid upland switchgrass cultivars.

\section{Agronomic traits of VT8-1, VT8-2, and hybrid plants}

The VT8-1 and VT8-2 plants, along with tetraploid HR8 plants and the natural octoploid switchgrass cv. Blackwell, were grown in the Kentland farm of Virginia Tech. We noticed that the VT8-1 and VT8-2 plants produced thicker and longer leaves, as well as thicker stems, in comparison to the parental tetraploid plants. Based on the emergence of the first flowering tiller, VT8-1 and VT8-2 also exhibited delayed flowering, by about 20 days, in comparison to the parental tetraploids. We measured the stomatal cell sizes of the autooctoploids under a 
microscope. As shown in Figure 3, the autooctoploids have larger cells but a decreased cell frequency per square unit area. The average stomata height $x$ length for VT8-1 and Alamo (HR8) was $70.63 \pm 5.31 \times 83.37 \pm 14.68$ and $42.81 \pm 3.75 \times 70.68 \pm 5.05$, respectively. However, VT8-1, VT8-2, and the hybrid plants derived from VT8-1 x Blackwell and Blackwell x VT8-1 crosses produced about 50\% less tillers in comparison to the cv. Alamo (HR8) (Table 3). Correspondingly, the autooctoploid plants produced 20-37\% less total dry biomass when grown under field conditions. Similarly, the hybrid plants also produced less biomass than that of $\mathrm{cv}$. Alamo (Table 3). Unfortunately, the Blackwell plants did not grow well in 2011. Therefore, we were not able to measure any reliable agronomic traits of cv. Blackwell and subsequently, we were not able to compare the dry biomass yields of the hybrids to the Blackwell plants.

\section{Discussion}

The generation of autooctoploid plant lines through chromosome doubling has been used to create novel germplasms in many breeding programs [19-25, 41]. The development of autopolyploid plants has also been used to overcome the cross incompatibility barrier between different ploidy levels [42-44]. In rice, hybridization of colchicine-induced autotetraploids of indica and japonica varieties displayed enhanced heterosis, which is a beneficial trait for crop improvement (Tu et al., 2007). A recent paper reported that hybrids derived from a cross between the tetraploid upland cv. Summer and the tetraploid lowland cv. Alamo produced more biomass than either parental line [17]. However, there are no switchgrass cultivars derived from crossing between tetraploid lowland and octoploid upland germplasms, mainly because of their different chromosome ploidy.

In this study, we report for the first time the generation of autooctoploid lowland switchgrass lines by chemically-induced chromosome doubling. The derived lowland autooctoploid lines can be crossed to the natural octoploid upland switchgrass cv. Blackwell (Figure 4 and 5). As shown in Table 3, the first two autooctoploid lines, and their derived hybrids, have reduced average dry biomass yield compared to the tetraploid cv. Alamo. Since the upland cv. Blackwell has a heterozygous genetic background, we observed that a small population of hybrids derived from the VT8-1 x Blackwell cross has a large variation in term of total biomass yields. This may suggest that certain genotypes of hybrids may have strong heterosis (data not 
shown). Further selection of hybrids derived from similar controlled crosses may allow us to breed new switchgrass cultivars with improved biomass yield and other agronomic traits.

In vitro chromosome doubling of switchgrass required efficient callus induction and proliferation. Xu et al. (2011) identified the switchgrass genotype HR8, a line derived from the cv. Alamo that has extremely high tissue culture capacity [33]. In this study, SE calli were induced from mature seeds of HR8. Then, the calli were treated with colchicine, which led us to regenerate thirteen autooctoploid switchgrass lines (Table 2). We demonstrate that SE callus can be treated either on solid or in liquid mediums and that both methods are efficient to induce chromosome doubling in switchgrass. For switchgrass, treatment duration, rather than chemical concentration, is the major factor that must be optimized in order to achieve the highest efficiency of chromosome doubling. Similar results have been reported in other plant species, such as Miscanthus [19] [24] and grass pea [29].

In comparison to the control plants, chromosome doubling generates autopolyploid plants that can have larger organ sizes, higher biomass yields, delayed flowering times, and improved cold tolerance; however, autopolyploid plants normally show decreased fertility [45]. It has also been reported that genome polyploidation can have potential selective advantages such as increased heterozygosity, as well as novel variation and allelic subfunctionalization [46-49]. However, the molecular mechanisms that contribute to the novel phenotypes of autopolyploidy plants remain largely unexplored [48-51]. Interestingly, one report has described the loss of selfincompatibility after polyploidation events [52]. However, in our study, all autooctoploid plants remained self-incompatible. Therefore, chromosome doubling in switchgrass cannot break the self-incompatibility barrier. We observed that all thirteen autooctoploid switchgrass lines have delayed flowering time, as well as increased stem size and leaf width. However, most of the autooctoploid switchgrass lines have significantly reduced tiller numbers (Table 3). Therefore, the total dry biomass yields are actually decreased in comparison to the tetraploid lines.

Switchgrass is highly self-incompatible and most new cultivars are generated through population selection [1,53]. For these new cultivars, a majority of the genes are still in heterozygous conditions. Therefore, it is difficult to compare agronomic traits and the genetic contributions between tetraploid and autooctoploid lines generated through chromosome doubling. In this study, we observed that individual plants of the tetraploid switchgrass cv. Alamo have significant diversity in terms of many visual agronomic traits (data not shown). To 
minimize the genetic difference between a particular tetraploid and the derived octoploid plants, we tried to generate SE callus from single mature switchgrass seeds. Theoretically, all SE calli derived from a single seed should have uniform or highly similar genetic backgrounds; however, we need to be cautious of somatic mutations that may be generated during the tissue culture steps. We generated multiple individual SE callus lines, making sure to regenerate both tetraploid and autooctoploid lines from the same SE callus. We observed that different tetraploid and autooctoploid lines have obvious alterations in phenotypes, but the tetraploid and its derived autooctoploid have similar agronomic phenotypes. This indicates that these lines have similar genetic contents but may differ in the dosage of each gene at certain loci. The autooctoploid switchgrass lines could be used as a model to illustrate the consequences of polyploidy on the genome and gene expression levels in switchgrass [51]. In this case, the pairs of tetraploid and autooctoploid lines derived from the same SE callus lines, with similar or close genetic backgrounds, could be used to identify genes that are differently regulated by chromosome doubling through expression profiling [54-56]. It was also recently reported that switchgrass SE callus could be generated from in vitro culture of inflorescences [57]. The inflorescence-derived SE calli should also have uniform genetic backgrounds. Therefore, that callus could also be suitable for generating autopolyploid lines for further studies.

Stomatal cell size and frequency have been used as indicators of ploidy level [24, 58, 59]. In this study, we observed that all of the autooctoploid switchgrass lines have larger stomatal cell sizes (Figure 3) than the tetraploid controls. This confirms that stomatal cell size could be a marker of putative autopolyploidy in switchgrass lines. However, we also observed that many switchgrass lines with larger stomatal cell sizes were later confirmed to be tetraploid using flow cytometry assays (data not shown). Therefore, it is more practical to use both stomatal cell size and flow cytometry assays as identifiers of autooctoploid switchgrass lines.

Recently, genome size variation of a core set of switchgrass germplasm was assayed by both flow cytometry and cytology. The results of this study suggests that aneuploidy is rampant in natural switchgrass populations [39]. In this study, we employed both flow cytometry and a root tip chromosome counting method to assay the genome size of the autooctoploids and their derived hybrid plants (Figure 2 and 4). Our results confirm that flow cytometry is accurate for evaluating ploidy level, but it may not be able to distinguish aneuploidy vs euploidy. As shown in Figure 4, both VT8-1 $(2 n=78)$ and VT8-2 $(2 n=76)$, derived from line HR8 $(2 n=38)$, are 
aneuploids. Other reports have revealed that switchgrass sampled from upland populations were primarily octoploid ( $2 n=72)$; however, some were aneuploid variants and chromosome numbers ranged from 66 to 77 [60]. VT8-1 has one more pair of chromosomes than expected, however, the hybrid of VT8-1 (2n=78) x Blackwell $(2 n=72)$ has 72 chromosomes. The reasons for these results are not quite clear. It was proposed that the large genome size of switchgrass may provide a genetic buffer for aneuploidy [39]. However, euploidy cultivars may still be important for improving genetic stability and selecting for uniformity of agronomic traits of released cultivars.

In summary, we successfully developed autooctoploid switchgrass lines from lowland cv. Alamo that can be used to cross to natural upland switchgrass lines to produce hybrids. The new switchgrass lines represent a critical resource for transferring useful agronomic traits from lowland to upland switchgrass cultivars. Hybrids between upland and lowland cultivars should allow us to maximize heterosis in order to develop new cultivars with super agronomic traits suitable for large-scale biomass production.

\section{Acknowledgement}

The authors thank Dr. Richard Veilleux for his valuable comments. This project was partly supported by a grant from the Institute of Critical Technology and Applied Sciences (ICTAS) of Virginia Tech, The Bioprocess and Biodesign Research Center of the Agricultural and Life Science College of Virginia Tech, the DOE (DE-FG02-08ER64629), the foundation of American Electric Power, and the Virginia Agricultural Research Station (VA135872). 
Table 1. Tissue culture mediums used in this study.

\begin{tabular}{ll}
\hline Medium Name & \multicolumn{1}{c}{ Medium Composition } \\
\hline Solid callus induction medium $(\mathrm{CI})$ & MS basal salts and vitamins, 3\% maltose, 22.5 $\mu \mathrm{M}$ 2,4-D, and \\
& $5 \mu \mathrm{M}$ 6-BA,0.8\% plant tissue culture agar \\
Liquid callus induction medium (LCI) & MS basal salts and vitamins, 3\% maltose, 22.5 $\mu \mathrm{M} 2,4-\mathrm{D}$, and \\
& $5 \mu \mathrm{M}$ 6-BA \\
Regeneration medium $(\mathrm{RG})$ & MS basal salts and vitamins, 3\% maltose, 0.8\% agar, and 1.44 \\
& $\mu \mathrm{M}$ gibberellic acid $\left(\mathrm{GA}_{3}\right), 0.8 \%$ plant tissue culture agar \\
\hline
\end{tabular}


Table 2. Autooctoploid plants regenerated from colchicine-treated callus in solid and liquid medium as determined by flow cytometry.

\begin{tabular}{|c|c|c|c|c|c|c|}
\hline & \multicolumn{2}{|c|}{ Treatment } & \multirow{2}{*}{$\begin{array}{l}\text { No. of treated } \\
\text { calli }\end{array}$} & \multirow{2}{*}{$\begin{array}{l}\text { No. of seedlings } \\
\text { regenerated from } \\
\text { treated calli }\end{array}$} & \multirow{2}{*}{$\begin{array}{l}\text { No. of seedlings } \\
\text { subjected to flow } \\
\text { cytometry }\end{array}$} & \multirow{2}{*}{$\begin{array}{l}\text { No. of } \\
\text { putative } \\
\text { octoploid }\end{array}$} \\
\hline & Colchicine (\%) & Day & & & & \\
\hline \multirow{10}{*}{ 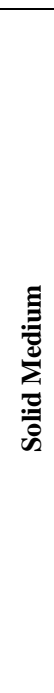 } & 0.01 & 2 & 45 & 93 & 6 & 0 \\
\hline & & 6 & 62 & 47 & 6 & 0 \\
\hline & & 13 & 51 & 29 & 6 & 0 \\
\hline & 0.01 & 2 & 68 & 44 & 6 & 0 \\
\hline & & 6 & 82 & 81 & 6 & 2 \\
\hline & & 13 & 57 & 16 & 6 & 0 \\
\hline & 0.03 & 2 & 45 & 127 & 6 & 0 \\
\hline & & 6 & 58 & 46 & 6 & 0 \\
\hline & & 13 & 114 & 78 & 6 & 2 \\
\hline & Sub-total & & 582 & 561 & 54 & 4 \\
\hline \multirow{14}{*}{ 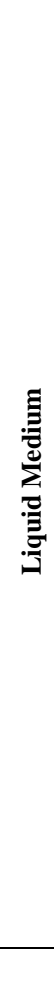 } & $0.02 \%$ & 2 & 156 & 95 & 10 & 0 \\
\hline & & 4 & 80 & 90 & 10 & 0 \\
\hline & & 6 & 91 & 31 & 10 & 1 \\
\hline & & 13 & 102 & 14 & 10 & 0 \\
\hline & $0.04 \%$ & 2 & 149 & 60 & 10 & 0 \\
\hline & & 4 & 74 & 48 & 10 & 1 \\
\hline & & 6 & 86 & 26 & 10 & 0 \\
\hline & & 13 & 91 & 14 & 10 & 2 \\
\hline & $0.06 \%$ & 2 & 120 & 91 & 10 & 0 \\
\hline & & 4 & 81 & 55 & 10 & 2 \\
\hline & & 6 & 88 & 15 & 10 & 0 \\
\hline & & 13 & 108 & 9 & 5 & 1 \\
\hline & Sub-total & & 1226 & 548 & 115 & 7 \\
\hline & Total & & & & & 11 \\
\hline
\end{tabular}


Table 3. Evaluation of the agronomic traits of two autooctoploid switchgrass lines and the hybrid plants derived from autooctoploid x natural upland octoploid cv. Blackwell. Plants were established in the field in 2010 and harvested in 2011.

\begin{tabular}{|c|c|c|c|c|c|c|}
\hline & $\begin{array}{c}\text { Dry Biomass } \\
\text { (gram) }\end{array}$ & $\begin{array}{c}\text { Tiller } \\
\text { Number }\end{array}$ & $\begin{array}{c}\text { Stem Size } \\
\text { (cm) }\end{array}$ & $\begin{array}{c}\begin{array}{c}\text { Leaf } \\
\text { Length }\end{array} \\
(\mathrm{cm})\end{array}$ & $\begin{array}{c}\text { Leaf Width } \\
\text { (cm) }\end{array}$ & $\begin{array}{c}\text { Plant } \\
\text { Height } \\
(\mathrm{cm})\end{array}$ \\
\hline VT8-1 & $218.8( \pm 14.4)^{* * *}$ & $34( \pm 5)^{* *}$ & $5.6( \pm 0.2)^{\circ}$ & $58.4( \pm 6)^{* *}$ & $1.87( \pm 0.08)^{* *}$ & $118.6( \pm 1.8)$ \\
\hline VT8-2 & $277.5( \pm 67.6)^{* *}$ & $37( \pm 8)^{* *}$ & $7.2( \pm 1.0)^{* *}$ & $57.7( \pm 5.7)^{* *}$ & $1.35( \pm 0.22)^{* *}$ & $114.2( \pm 8.8)$ \\
\hline VT8-1xBlackwell & $157.5( \pm 178.5)$ & $55( \pm 44)$ & $4.36( \pm 0.53)$ & $37.6( \pm 4.9)$ & $1.05( \pm 0.7)$ & $95.4( \pm 14.8)$ \\
\hline Blackwell xVT8-1 & $187.5( \pm 45.0)$ & $68( \pm 32)$ & $4.17( \pm 0.78)$ & $41.5( \pm 4.3)$ & $1.12( \pm 0.9)$ & $92.7( \pm 7.1)$ \\
\hline Alamo (HR8) & $351.3( \pm 157.4)$ & $77( \pm 29)$ & $4.49( \pm 0.86)$ & $42.1( \pm 4.6)$ & $1.21( \pm 1.8)$ & $118.7( \pm 18.8)$ \\
\hline
\end{tabular}

${ }^{\mathrm{c}} \mathrm{SE}$ (standard error) is in parenthesis. ${ }^{* *}$ Statistically significant differences $(\mathrm{p}<0.01)$ between autooctoploid lines and Alamo control. 

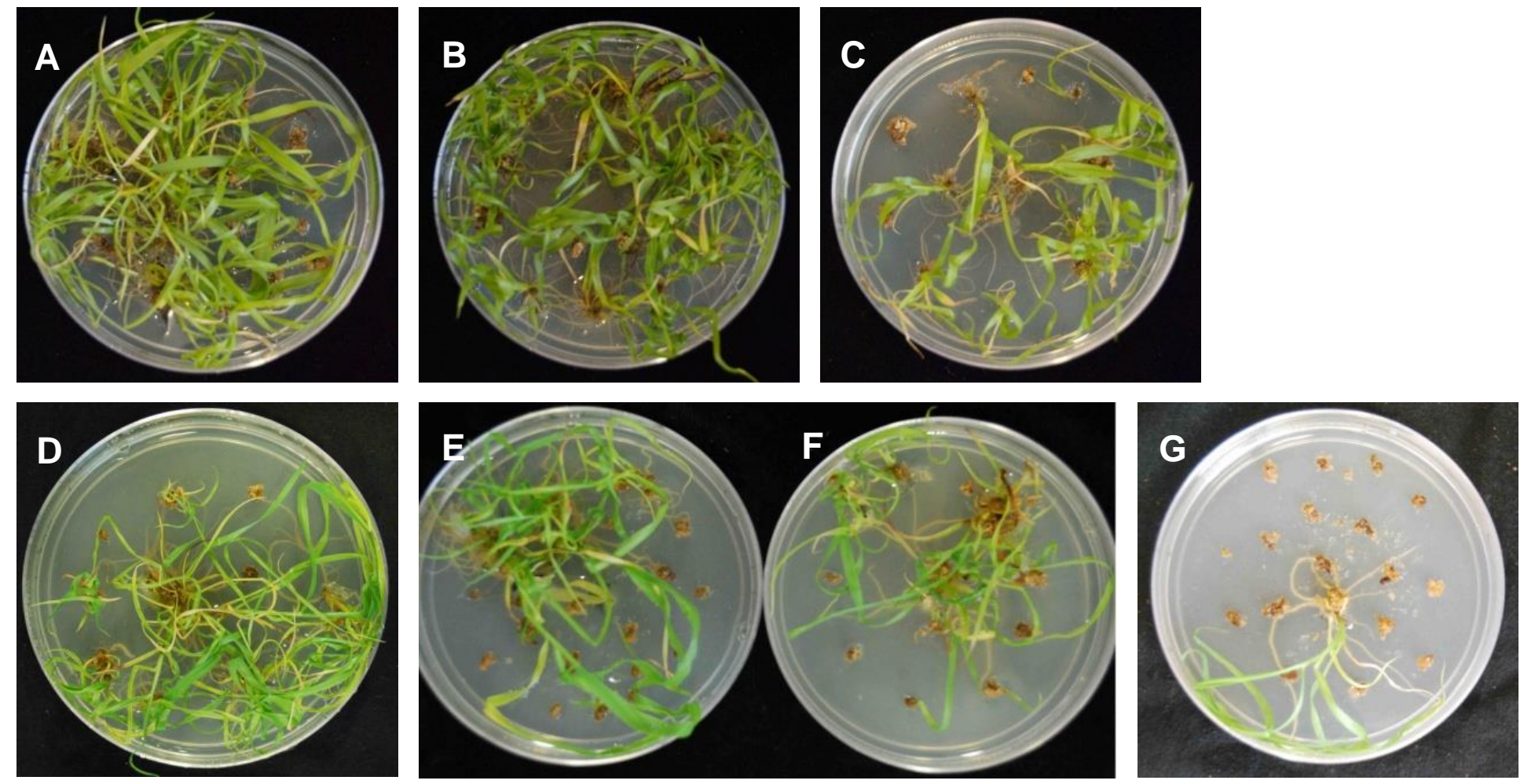

Figure 1. Switchgrass seedlings were regenerated from SE calli after treated with various concentrations of colchicine and durations on solid and liquid medium. $A, B$ and $C$ show that calli were treated in solid media with $0.02 \%$ of colchicine for 2,6 and 13 days respectively. $D, E, F$ and $G$ show that calli were treated in liquid media with $0.02 \%$ of colchicine for $2,4,6$ and 13 days respectively. 

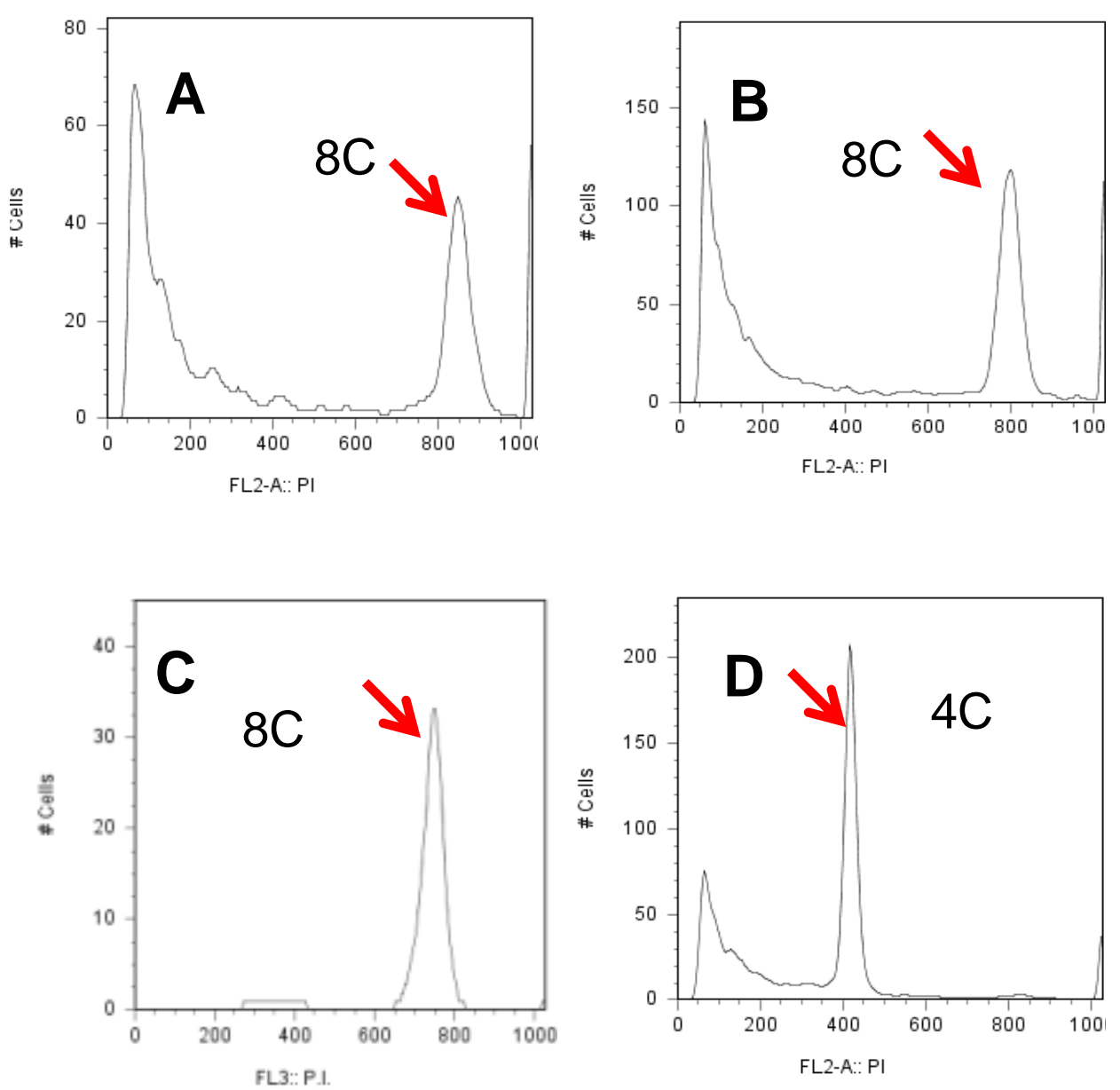

Figure 2. The nuclei DNA content of switchgrass lines was determined by flow cytometry. (A) autooctoploid VT8-1, (B). autooctoploid VT8-2, (C) The natural octoploid cv. Blackwell, (D) The tetraploid cultivar Alamo (HR8). Nuclei were stained with propidium iodide $(\mathrm{PI})$, and the ploidy level of each peak is indicated as $4 \mathrm{C}$ and $8 \mathrm{C}$. 

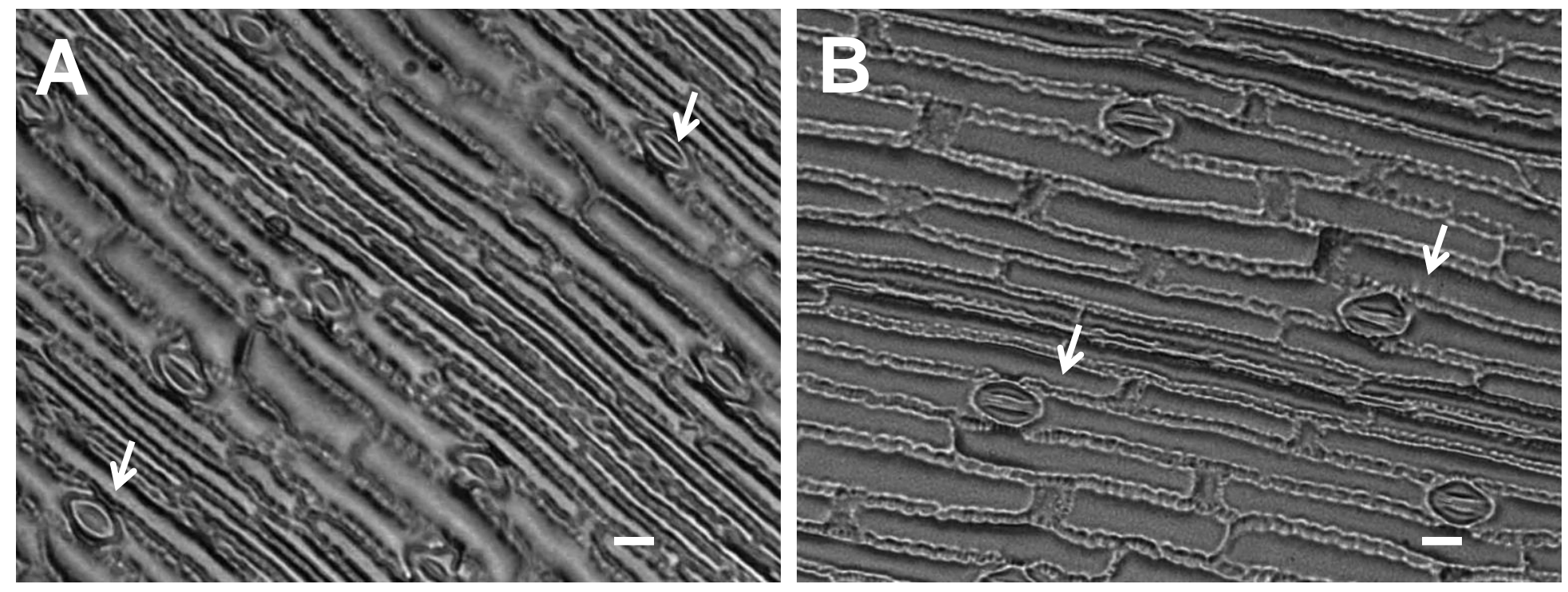

Figure 3. The epidermal and stomata cells were examined under light microscopy (10x). (A) The tetraploid cv. Alamo (HR8). (B) The autooctoploid line VT8-1. The bars represent $5 \mu \mathrm{m}$. The arrows point top stomata. Average stomata height $x$ length for VT8-1 and Alamo (HR8) is $70.63 \pm 5.31 \times 83.37 \pm 14.68$ and $42.81 \pm 3.75 \times 70.68 \pm 5.05$, respectively. 


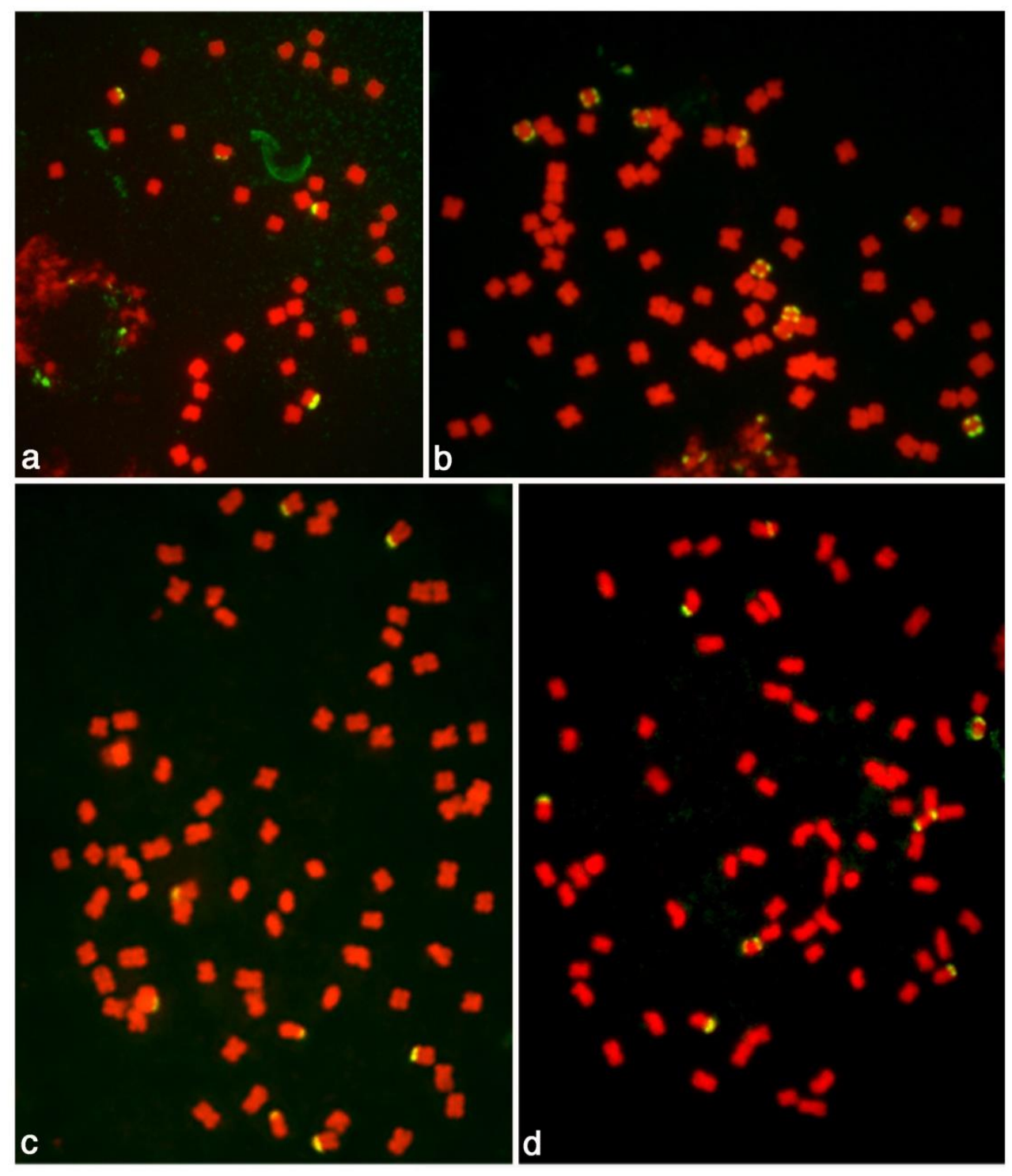

Figure 4: Fluorescence in situ hybridization pattern using clone pTa71 (18-25 S rDNA, NOR) as a probe on mitotic metaphase chromosomes of switchgrass.

(A) HR8, 2n=4x=38, 4 telomeric NORs; (B) Blackwell, $2 n=8 x=72$, 6 iso plus 2 interstitial NORs; (C) VT8-2, $2 \mathrm{n}=8 \mathrm{x}=76,8$ telomeric NORs; and (D) Blackwell x VT8$1,2 n=8 x=72,3$ iso plus 4 telomeric plus one interstitial NOR; pTa71 was labeled with FITC detected by yellow-green fluorescence and chromosomes were counterstained with propidium iodide and fluoresce red. 


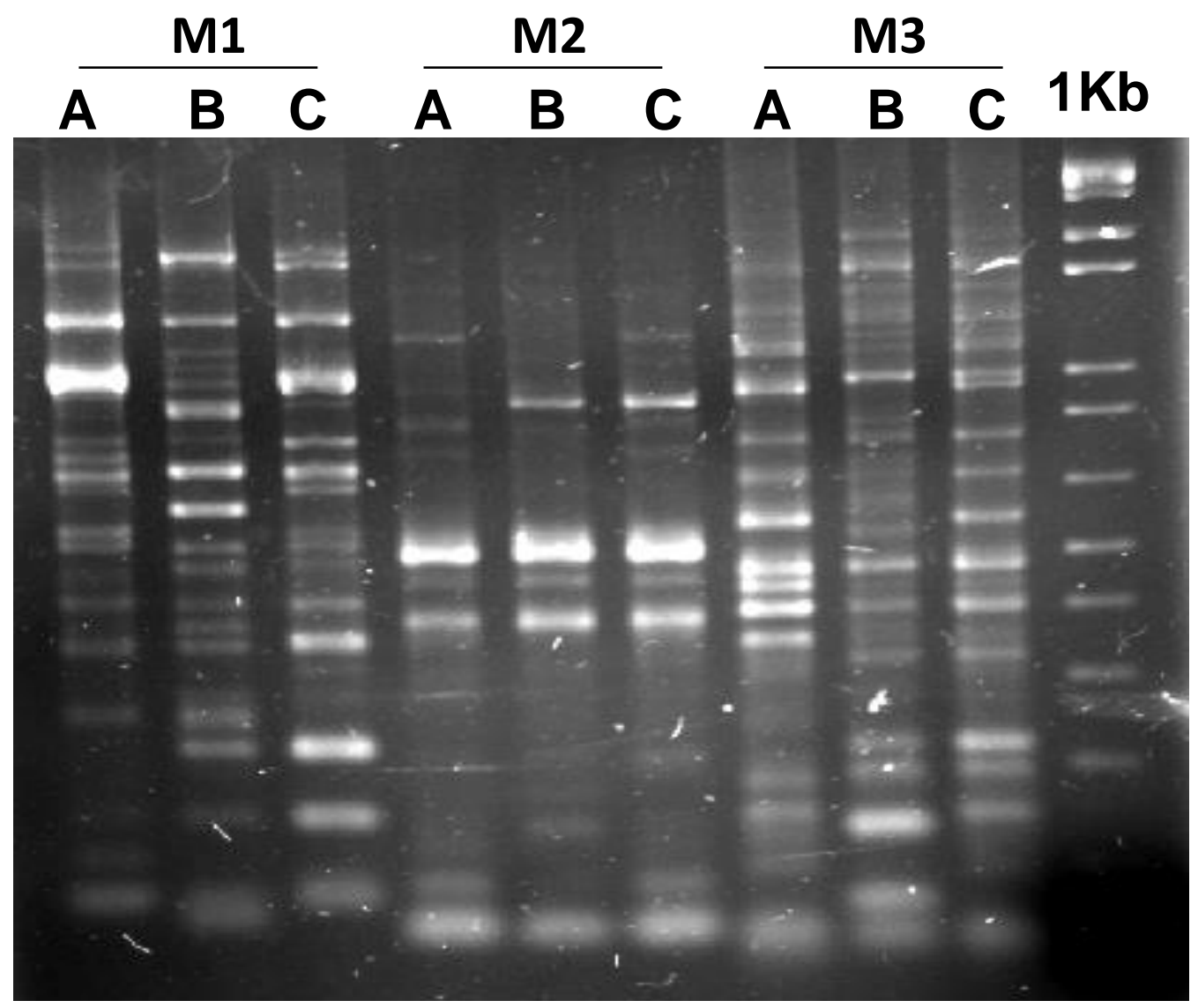

Figure 5. Genotyping the hybrid plant derived from VT8-1 x Blackwell by molecular markers. (A) VT81, (B) Blackwell, (C) Hybrid plant derived from Blackwell x VT8-1. M1, M2, and M3 are three SRAPPCR markers. The most right lane is the $1 \mathrm{~Kb}$ DNA ladder. 

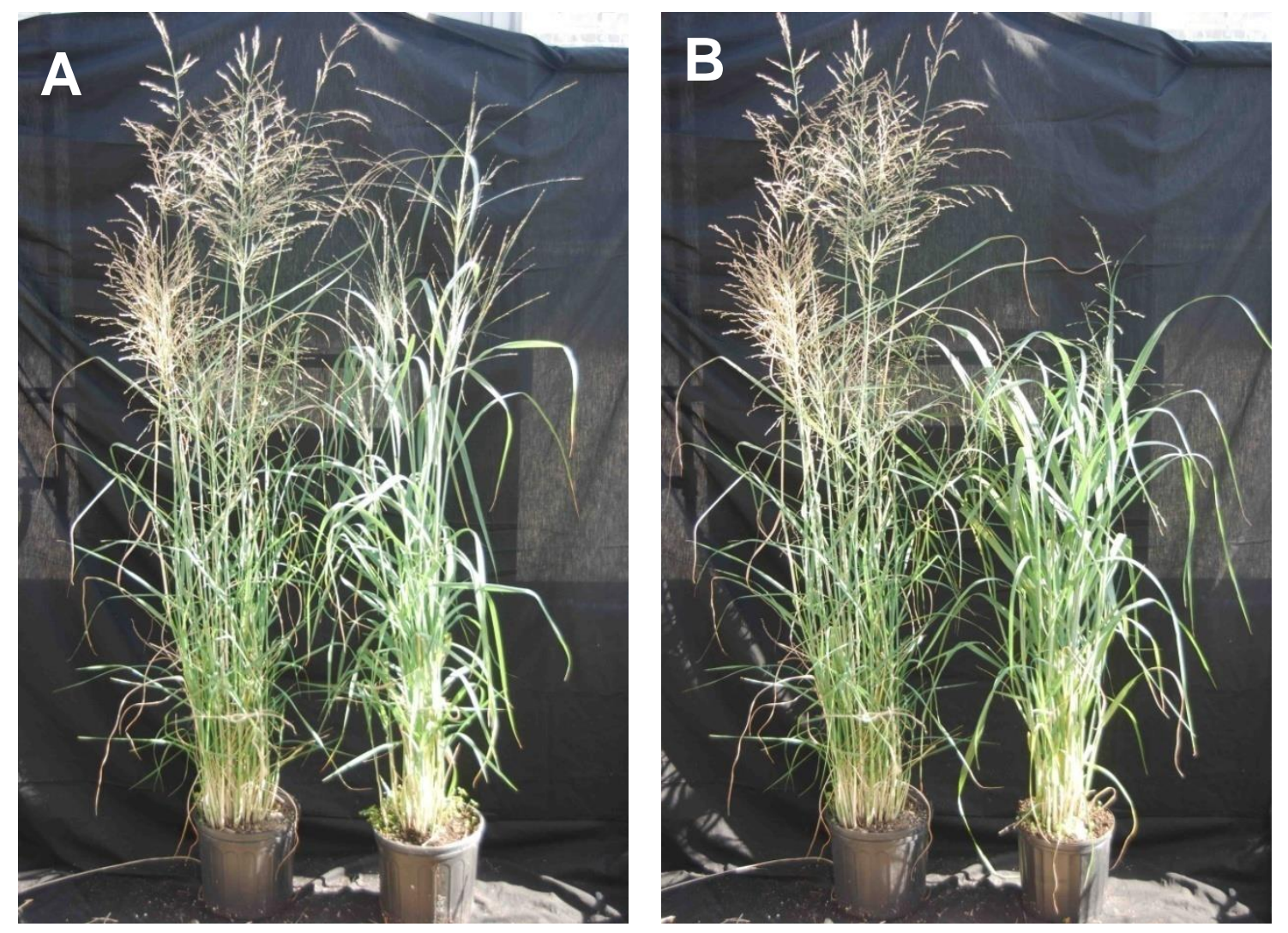

Figure 6. The morphology of two autooctoploid plants and the tetraploid cv. Alamo (HR8) maintained in greenhouse. All plants were transplanted from a tiller with similar age/size from the original plants derived from tissue culture process. (A) HR8 (Left) and VT8-1 (right). (B) HR8 (left) and VT8-2 (right). 


\section{References}

1. Bouton JH (2007) Molecular breeding of switchgrass for use as a biofuel crop. Curr Opin Genet Dev 17(6): 553-558.

2. Hartman JC, Nippert JB, Orozco RA, Springer CJ (2011) Potential ecological impacts of switchgrass (Panicum virgatum L.) biofuel cultivation in the central great plains, USA. Biomass Bioenergy 35(8): 3415-3421.

3. Cornelius D. R, Johnston C. O (1941) Differences in plant type and reaction to rust among several collections of Panicum virgatum L. . J Am Soc Agron 33: 115-124.

4. Barney JN, Mann JJ, Kyser GB, Blumwald E, Van Deynze A, DiTomaso JM (2009) Tolerance of switchgrass to extreme soil moisture stress: Ecological implications. Plant Sci 177(6): 724-732.

5. Parrish DJ, Fike JH (2005) The biology and agronomy of switchgrass for biofuels. Crit Rev Plant Sci 24(5): 423-459.

6. Parrish DJ, Fike JH (2009) Selecting, establishing, and managing switchgrass (Panicum virgatum) for biofuels. Biofuels: Methods and Protocols: 27-40.

7. Martinez-Reyna JM, Vogel KP (2002) Incompatibility systems in switchgrass. Crop Sci. 42(6): 1800-1805.

8. Martinez-Reyna JM, Vogel KP, Caha C, Lee DJ (2001) Meiotic stability, chloroplast DNA polymorphisms, and morphological traits of upland $\mathrm{x}$ lowland switchgrass reciprocal hybrids. Crop Sci 41(5): 1579-1583.

9. Huang S, Su X, Haselkorn R, Gornicki P (2003) Evolution of switchgrass (Panicum virgatum $\mathrm{L}$.) based on sequences of the nuclear gene encoding plastid acetyl-CoA carboxylase. Plant Sci 164(1): 43-49.

10. Missaoui A, Paterson A, Bouton J (2006) Molecular markers for the classification of switchgrass (Panicum virgatum L.) germplasm and to assess genetic diversity in three synthetic switchgrass populations. Genet Resour Crop Ev 53(6): 1291-1302.

11. Zalapa JE, Price DL, Kaeppler SM, Tobias CM, Okada M, MD. C (2011) Hierarchical classification of switchgrass genotypes using SSR and chloroplast sequences: ecotypes, ploidies, gene pools, and cultivars. Theor Appl Genet 122(4): 805-817.

12. Okada M, Lanzatella C, Tobias C (2011) Single-locus EST-SSR markers for characterization of population genetic diversity and structure across ploidy levels in switchgrass (Panicum virgatum L.). Genet Resour Crop Ev 58(6): 919-931.

13. Cortese L, Honig J, Miller C, Bonos S (2010) Genetic diversity of twelve switchgrass populations using molecular and morphological markers. Bioenerg Res 3(3): 262-271.

14. Narasimhamoorthy B, Saha M, Swaller T, Bouton J (2008) Genetic diversity in switchgrass collections assessed by EST-SSR markers. Bioenerg Res 1(2): 136-146.

15. Lippman ZB, Zamir D (2007) Heterosis: revisiting the magic. Trends Genet 23(2): 6066.

16. Dhugga KS (2007) Maize biomass yield and composition for biofuels. Crop Sci 47(6): 2211-2227.

17. Martinez-Reyna JM, Vogel KP (2008) Heterosis in Switchgrass: Spaced Plants. Crop Sci 48(4): 1312-1320.

18. Taliaferro C, Breeding and selection of new switchgrass varieties for increased biomass production, in Annual report from Oklahoma State Univ. to Oak Ridge National Laboratory, 1998, ORNL/SUB-02-19XSY162C/01. Oak Ridge, TN: Oak Ridge National Laboratory. Online at http://www.ornl.gov/info/reports/2002/3445605360105.pdf. 
19. Petersen KK, Hagberg P, Kristiansen K (2002) In vitro chromosome doubling of Miscanthus sinensis. Plant Breeding 121(5): 445-450.

20. Leblanc O, Duenas M, Hernandez M, Bello S, Garcia V, Berthaud J, Savidan Y (1995) Chromosome doubling in tripsacum-the production of artificial, sexual tetraploid plants. Plant Breeding 114(3): 226-230.

21. Chen JF, Kirkbride JH (2000) A new synthetic species of Cucumis (Cucurbitaceae) from interspecific hybridization and chromosome doubling. Brittonia 52(4): 315-319.

22. Rhoades MM, Ellen D (1966) Induction of chromosome doubling at meiosis by the elongate gene in maize. Genetics 54 (2): 505-522.

23. Hansen NJP, Andersen SB (1998) In vitro chromosome doubling with colchicine during microspore culture in wheat (Triticum aestivum L.). Euphytica 102(1): 101-108.

24. Yu CY, Kim HS, Rayburn AL, Widholm JM, Juvik JA (2009) Chromosome doubling of the bioenergy crop, Miscanthus $\times$ giganteus. GCB Bioenergy 1(6): 404-412.

25. Birchler JA, Auger DL, Riddle NC (2003) In search of the molecular basis of heterosis. Plant Cell 15(10): 2236-2239.

26. Randolph LF (1932) Some effects of high temperature on polyploidy and other variations in maize. Proc Natl Acad Sci U S A. 18(3): 222-229.

27. Fankhauser G, Watson RC (1942) Heat-Induced triploidy in the newt, Triturus Viridescens. Proc Natl Acad Sci U S A 28(10): 436-40.

28. Kato A, Birchler JA (2006) Induction of tetraploid derivatives of maize inbred lines by nitrous oxide gas treatment. J Hered 97(1): 39-44.

29. Dibyendu T (2010) Cytogenetic characterization of induced autotetraploids in grass pea (Lathyrus sativus L.). Caryologia 63(1): 62-72.

30. Kermani MJ, Sarasan V, Roberts AV, Yokoya K, Wentworth J, Sieber VK (2003) Oryzalin-induced chromosome doubling in Rosa and its effect on plant morphology and pollen viability. Theor Appl Genet 107(7): 1195-1200.

31. Kato A (1999) Air drying method using nitrous oxide for chromosome counting in maize. Biotech Histochem 74(3): 160-6.

32. Kato A, Lamb JC, Birchler JA (2004) Chromosome painting using repetitive DNA sequences as probes for somatic chromosome identification in maize. Proc Natl Acad Sci U S A 101(37): 13554-13559.

33. Xu B, Huang L, Shen Z, Welbaum GE, Zhang X, Zhao B (2011) Selection and characterization of a new switchgrass (Panicum virgatum L.) line with high somatic embryogenic capacity for genetic transformation. Scientia Horticulturae 129(4): 854-861.

34. Gerlach WL, Bedbrook JR (1979) Cloning and characterization of ribosomal RNA genes from wheat and barley. Nucleic Acids Res. 11(7): 1869-1885.

35. Missaoui AM, Paterson AH, Bouton JH (2005) Investigation of genomic organization in switchgrass (Panicum virgatum L.) using DNA markers. Theor Appl Genet 110(8): 1372-83.

36. Li G, Quiros CF (2001) Sequence-related amplified polymorphism (SRAP), a new marker system based on a simple PCR reaction: its application to mapping and gene tagging in Brassica. Theor Appl Genet 103(2): 455-461.

37. Huang L-K, Bughrara SS, Zhang X-Q, Bales-Arcelo CJ, Bin X (2011) Genetic diversity of switchgrass and its relative species in Panicum genus using molecular markers. Biochem Syst Ecol 39(4): 685-693. 
38. Martinez-Reyna JM, Vogel KP (2002) Incompatibility Systems in Switchgrass. Crop Sci 42(6): 1800-1805.

39. Costich DE, Friebe B, Sheehan MJ, Casler MD, Buckler ES (2010) Genome-size variation In switchgrass (panicum Virgatum): flow cytometry and cytology reveal rampant aneuploidy. Plant Genome 3(3): 130-141.

40. Rahman M, McVetty PB, Li G (2007) Development of SRAP, SNP and multiplexed SCAR molecular markers for the major seed coat color gene in Brassica rapa $\mathrm{L}$. Theor Appl Genet 115(8): 1101-7.

41. Tu S, Luan L, Liu Y, Long W, Kong F, He T, Xu Q, Yan W, Yu M (2007) Production and Heterosis analysis of rice autotetraploid hybrids. Crop Sci 47(6): 2356-2363.

42. Chavez DJ, Lyrene PM (2009) Production and identification of colchicine-derived tetraploid vaccinium darrowii and its use in breeding. J Am Soc Hortic Sci 134(3): 356363.

43. Dweikat IM, Lyrene PM (1991) Induced tetraploidy in a Vaccinium elliottii facilitates crossing with cultivated highbush blueberry J Am Soc Hortic Sci 116(6): 1063-1066

44. Baum M, Lagudah ES, Appels R (1992) Wide crosses in cereals. Annu Rev Plant Physiol Plant Mol Biol 43(1): 117-143.

45. Poehlman J, (1986) Variations in chromosome number. In: Westport C (ed) Breeding field crops, 3rd edn., Avi Publishing Company, pp 87-108.

46. Leitch IJ, Bennett MD (1997) Polyploidy in angiosperms. Trends Plant Sci 2(12): 470476.

47. Wendel JF (2000) Genome evolution in polyploids. Plant Mol Biol 42(1): 225-49.

48. Chen ZJ, Ni Z (2006) Mechanisms of genomic rearrangements and gene expression changes in plant polyploids. Bioessays 28(3): 240-52.

49. Chen ZJ (2010) Molecular mechanisms of polyploidy and hybrid vigor. Trends Plant Sci 15(2): 57-71.

50. Doyle JJ, Egan AN (2010) Dating the origins of polyploidy events. New Phytol 186(1): 73-85.

51. Parisod C, Holderegger R, Brochmann C (2010) Evolutionary consequences of autopolyploidy. New Phytol 186(1): 5-17.

52. Miller JS, Venable DL (2000) Polyploidy and the evolution of gender dimorphism in plants. Science 289(5488): 2335-8.

53. Casler M, (2012) Switchgrass breeding, genetics, and genomics. In: Monti A (ed) Switchgrass, green energy and technology, London, Springer-Verlag, pp 29-53.

54. Stupar RM, Bhaskar PB, Yandell BS, Rensink WA, Hart AL, Ouyang S, Veilleux RE, Busse JS, Erhardt RJ, Buell CR, Jiang J (2007) Phenotypic and transcriptomic changes associated with potato autopolyploidization. Genetics 176(4): 2055-67.

55. Yu Z, Haberer G, Matthes M, Rattei T, Mayer KF, Gierl A, Torres-Ruiz RA (2010) Impact of natural genetic variation on the transcriptome of autotetraploid Arabidopsis thaliana. Proc Natl Acad Sci U S A. 107(41): 17809-14.

56. Hovav R, Udall JA, Chaudhary B, Rapp R, Flagel L, Wendel JF (2008) Partitioned expression of duplicated genes during development and evolution of a single cell in a polyploid plant. Proc Natl Acad Sci U S A. 105(16): 6191-5.

57. Burris J, Mann D, Joyce B, Stewart C (2009) An improved tissue culture system for embryogenic callus production and plant regeneration in switchgrass (Panicum virgatum L.). Bioenerg Res 2(4): 267-274. 
58. Beck SL, Dunlop RW, Fossey A (2003) Stomatal length and frequency as a measure of ploidy level in black wattle, Acacia mearnsii (de Wild). Bot J Linn Soc 141(2): 177-181.

59. Gu XF, Yang AF, Meng H, Zhang JR (2005) In vitro induction of tetraploid plants from diploid Zizyphus jujuba Mill. cv. Zhanhua. Plant cell reports 24(11): 671-6.

60. Brunken JN, JR E (1975) Cytological and morphological variation in Panicum virgatum L. Southwest Nat 19: 379-385. 